1 DOI: https://doi.org/10.47391/JPMA.405

2

3 Individualised cognitive behaviour therapy in patients of

4 substance use disorders: three case studies

5

6 Mafia Shahzadi ${ }^{1}$, Qasir Abbas ${ }^{2}$

71 DHQ Hospital Sheikhupura, Pakistan; 2 Department of Applied Psychology, Government

8 College University Faisalabad, Faisalabad, Pakistan

9 Correspondence: Mafia Shahzadi Email: mafia.mahak@yahoo.com

\title{
11 Abstract
}

12 The current study aims to investigate the effectiveness of Cognitive Behaviour 13 Therapy (CBT) in the treatment of patients with substance use disorders. Three 14 diagnosed patients with substance use disorders were recruited -i.e. 305.20 15 (F12.10) cannabis used disorder, 291.81 (FI0.239) alcohol withdrawal disorder 16 and 292.0 (F11.23) opioid withdrawal disorder, respectively. The patients were 17 detoxified and individual treatment plan was formulated on the basis of CBT. 18 The CBT therapeutic outcomes were evaluated on the basis of pre- and post19 assessment scores. Results indicate that CBT worked effectively in one-on-one session. CBT effectively worked to manage patients' anger, craving, stress, sleep hygiene and assertive behaviour. It is concluded that CBT is an effective approach to deal with patients' anger, stress, craving, sleep and assertive

23 behaviour.

24 Keywords: Cognitive Behavioural Therapy; Canabis Used Disorder; Alcohol

25 Withdrwal Disorder; Opioid Withdrawal Disorder

Introduction

27 Substance use disorder (SUD) is a global psychiatric problem which has a high 28 rate of mortality and morbidity ${ }^{1}$. For example, some adults use alcohol 
occasionally and some use it frequently, which causes deaths and others psychological as well as medical problems. ${ }^{2}$ According to an estimate, in the United States around 55\% adults of age 26 years consumed alcohol monthly and one fourth of the adults are involved in binge drinking which has harmful consequences. ${ }^{3}$ Moreover, in the US 15.1 million adults met diagnostic criteria for alcohol-use disorder in the past 12 months which causes numerous mental health problems among individuals. ${ }^{4}$ In Asian countries, the use of illicit drugs is increasing as well. In Asian countries drug prevalence is about 0.01\% $4.6 \% .^{5}$

The prevalence rate of substance use-related disorders is also high in Pakistan. According to a survey report by UNODC, 6.7\% individuals used an illegal drug in the past year and $4.3 \%$ individuals are suffering from substance use disorders and they need urgent treatment. This rate is increasing. For example, it was estimated that in 1980, 50,000 individuals were using some sort of substance, which increased to 6.2 million in 2006, 8.1 million in 2011 and since 2013 drug abuse prevalence is increasing rapdily. ${ }^{6}$ In Pakistan, heroin was not virtually in use around the 1980s, while 1990s saw an increasing heroin use. ${ }^{7}$ The Ministry of Narcotics Control Pakistan and the United Nations Office on Drugs and Crime released a collaborative report on drug use in Pakistan in 2013. This report describes that cannabis is the most common drug used in Pakistan by people aged between 15 and 64, while opiate use (opium or heroin) is widespread in one percent of the population. ${ }^{8}$

Substance use disorders are treatable and manageable psychiatric problems. After detoxification, cognitive behaviour therapy (CBT) is an evidence-based therapy for substance use disorders. It can be given as group therapy but it is more effective in one-on-one sessions. CBT particularly targets patients' behavioural and cognitive problems. The current study was planned to investigate the effectiveness of CBT in patients of Canabis use disorder, Alcohol withdrwal disorder and Opioid withdrawal disorder. ${ }^{9-10}$ 


\section{Patients and Methods}

After getting permission from the Ethical Review Committee, three cases were studied using case study method at the DHQ hospital Shekhupura from June 2018 to February 2019. After getting consent from the patients, treatment was started. In depth clinical interviews were conducted. Further, Alcohol Smoking and Substance Involvement Screening Test (ASSIT) and Addiction Severity Index (ASI) tests were used for screening and assessment of the patients. Patients' scores on both scales are shown in Table 1 and 2. Patients were diagnosed according to DSM-5. Patient "A" was a 29-year-old married man diagnosed with [305.20 (F12.10)] cannabis use disorder. Patient "B" was a 27year-old man, diagnosed with [291.81 (FI0.239)] alcohol withdrawal disorder. Patient "C" was a 20-year-old man, diagnosed with [292.0 (F11.23)] opioid withdrawal disorder. Further, 18 to 20 CBT-based therapeutic sessions were provided to each patient. Each CBT session was conducted as agenda-based session. Further, patients' follow up sessions were also conducted for three months and they were educated about the lapse and relapse preventions.

Pre- and post-screening tools: Novaco Anger Scale, a 25 item self-reported measure which assesses an individual's anger intensity in response to provoking situations, was used. ${ }^{11}$ The test-retest reliability of NAS is .89. Furthermore, Brief Substance Craving Scale is an 8 items self-report tool that measures the level of craving for substance abuse. ${ }^{12}$ Perceived Stress Scale was used to measure the perception of stress. ${ }^{13}$ Adolescent Sleep Hygiene Scale is a selfreport measure which assesses overall sleep hygiene. ${ }^{14}$ Rathus Assertiveness Scale contains 30 items which are intended to assess an individual's level of assertiveness. ${ }^{15}$ Significant difference was found between pre- and post-testing scores. (Figure-1).

\section{Discussion}

Findings reveal that cognitive behaviour or therapy (CBT) played a significant role in reducing anger, craving, and stress in patients. (Table-3). Furthermore, it 
87

increases the quality of sleep and assertive behaviour in patients. These findings are consistent with the findings of previous studies. CBT trails play a positive role in the treatment of cannabis use disorder and it becomes more effective when used along with medication. ${ }^{16}$ It is evidenced that the nature of SUD affects patients' physiological, psychosocial and social function and CBT substantially helps to treat these factors. Moreover, CBT is an evidence-based approach which has been identified as an effective cognitive and behavioural treatment approach for SUD patients. In this study, individualised CBT sessions were provided to SUD patients and the outcomes were effective. ${ }^{17}$ It was observed that CBT worked effectively with alcohol and opioid withdrawal disorders at the rehabilitation facility. After the detoxification process, patients felt more comfortable to stay in therapeutic sessions. A previous study has also shown that the combination of pharmacotherapy and CBT produce the best outcomes for treating patients with substances use disorder.

CBT is a goal-directed approach which focuses on the current position of patients and mainly targets the patient's maladaptive cognitive, behavioural and emotional patterns. ${ }^{15}$ Additionally, CBT techniques and planning of treatment particularly target the patient's core beliefs. If the patient's illogical and irrational beliefs change into logical and rational beliefs, the patient starts to believe that he is able to cope with his problems and his problems are manageable. In the current study, structured CBT sessions were conducted with the patients individually. Each session was formulated with a particular goal and agenda. The main focus was on the patients' cognitive restructuring, stress management, daily living functioning, and lapse-relapse preventions. Patients' cognitive and behavioral functioning significantly improved. It was also observed that they tried to cope with their problems such as craving. CBT work effectively with alcohol and illicit drugs. ${ }^{18}$ Research also revealed that the durability of treatment also affects the results. For instance, one study by Rawson and colleagues described that $60 \%$ of patients in CBT state gave clean 
116 toxicology screens at 52-week follow-up. ${ }^{19}$ By following the CBT technique, a

117 marked difference in the pre- and post-rating of the problems was noticed. It

118 was also concluded that contingency is very effective in substance use disorder

119 patients. Additionally, deficits in abilities for handling with antecedents and

120 consequences of substances are measured as a major contributor to the

121 development of SUDs. An individual with SUDs does not use appropriate skills

122 to overcome life stressors in an effective way. The reduced use of trained habits

123 and skills significantly leads to SUDs. ${ }^{20}$

124 In this current research, the technique "skill training" also known as "skills

125 building” was used on substance use disorder patients. In the process of skills

126 building, the patient's emotions, cognitive, behaviour, organisational,

127 interpersonal and problem-solving deficits were targeted. The approaches that

128 were based on patients's individual differences were used. The patient's

129 connection with others was worked on because the opposite of addiction is not

130 sobriety; in fact, it's the connection with society. In the current research, the

131 focus was on the patient's interpersonal skills as well. Interpersonal skills help

132 to remove relationship complications, enhance effective communication and

133 capability to use effective communication and social support. This support helps

134 in obtaining abstinence and healthy relationship. ${ }^{21}$

135 Conclusion

136 It is concluded that Cognitive Behaviour Therapy is an effective treatment

137 approach for the treatment of substance use disorders. It effectively works to

138 improve the patients' cognitive, behavioural and occupational functioning.

140 Limitations of the study

141 The study is rich in information but has some limitations. The patients showed 142 moderate level of interest in homework assignments, and wished to increase the 143 session interval when they felt they are improving but this factor was conrolled 144 through continous motivations. Moreover, the patients apparently had lower 
145 level of family, social and moral support during treatment; it is felt that if these 146 were present better results would be achieved.

148 Disclaimer: None

149 Conflict of Interest: None

150 Funding Sources: None

151

\section{References}

1. Harford TC, Yi HY, Grant BF. Other-and self-directed forms of violence and their relationships to DSM-IV substance use and other psychiatric disorders in a national survey of adults. Comp Psyc,2013;54:731-739.

2. World Health Organisation, Global Status Report on Alcohol and Health, 2018. Retrived on May 9, 2020 from www.who.int/substance_abuse/publications/global_alcohol_report/en/.

3. Substance Abuse and Mental Health Services Administration, Key substance use and mental health indicators in the United States: Results from the 2017 National Survey on Drug Use and Health (HHS Publication No. SMA 18-5068, NSDUH Series H-53) (2018). Retreved on May 09, 2020 from www.samhsa.gov/data/.

4. Center for Behavioural Health Statistics and Quality, Substance Abuse and Mental Health Services Administration, Key substance use and mental health indicators in the United States: Results from the 2015 National Survey on Drug Use and Health (HHS Publication No. SMA 164984, NSDUH Series H-51) (2016); Retrieved on May 4, 2020 from www.samhsa.gov/data/.

5. Otto MW, Smits JAJ Reese HE. Combined psychotherapy and pharmacotherapy for mood and anxiety disorders in adults: Review and analysis. Clinical Psychology: Sci \&Prac. 2005;12:72-86. 
6. UNODC. Drug use in Pakistan. Ministry of Interior and Narcotics Control Division. Pakistan. 2013; Retrieved on May 9, 2020 from https://www.unodc.org/documents/pakistan/Survey Report Final 2013.pdf

7. United Nations. The Millennium Development Goals Report 2009. New York: United Nations Department of Economic and Social Affairs. 2009. $\begin{array}{llll}\text { Rerieved on } & \text { May } & 920\end{array}$ from https://www.un.org/en/development/desa/publications/millennium-development-goalsreport-2009.html

8. National Institute of Mental Health (NIMH). National Comorbidity Survey: Lifeline prevalence estimate, 2007. Retrieved on May 3, 2020 from www.hcp.med. Harvard.edu

9. Palpacuer C, Duprez R, Huneau A, Locher C, Boussageon R, Laviolle B, Naudet F. Pharmacologically controlled drinking in the treatment of alcohol dependence or alcohol use disorders: A systematic review with direct and network meta-analyses on nalmefene, naltrexone, acamprosate, baclofen and topiramate. Addiction, 2018; 113, 220-237

10. McHugh RK, Votaw VR, Barlow DH, Fitzmaurice GM, Greenfield SF, Weiss RD. Development of an integrated cognitive behavioural therapy for anxiety and opioid use disorder: Study protocol and methods. Contemp Clin Trials. 2017;60:105-112. doi:10.1016/j.cct.2017.07.006

11.Novaco RW. The Novaco Anger Scale and Provocation Inventory (NASPI) Manual. Los Angeles: Western Psychological Services. 2003. $\begin{array}{lllll}\text { Retrieved on } & \text { May } & \text { 09, } & \text { from }\end{array}$ https://www.researchgate.net/publication/51214362 The Novaco Anger ScaleProvocation Inventory 1994 Version in Dutch Forensic Psychiatric Patients

12.Somoza E, Dyrenforth S, Goldsmith J, Mezinskis J, Cohen M. In search of a universal drug craving scale. Paper presented at the Annual Meeting of the American Psychiatric Association, Miami Florida. 1995;

13.Cohen S, Kamarck T, Mermelstein R. A global measure of perceived stress. J Heal Soc Beh. 1983;24: 386-396. 
14. Storfer-Isser A, LeBourgeois MK, Harsh J, Tompsett CJ, Redline S. Psychometric Properties of the Adolescent Sleep Hygiene Scale (ASHS). J Sleep Res. 2013;22: doi:10.1111/jsr.12059

15. Rathus SA. A 30-item schedule for assessing assertive behaviour. Behaviour Therapy, 1973;4:398-406. doi: 10.1016/s00057894(73)80120-0.

16. Guven F M, Camsari U M, Senormanci O, Oguz G. Cognitive behavioural therapy in cannabis use disorder. In V. R. Preedy (Ed.), Handbook of cannabis and related pathologies: Biology, pharmacology, diagnosis, and treatment , 2017; p. 1056-1065. https://doi.org/10.1016/B978-0-12-800756-3.00127-7

17. Witkiewitz K, Litten RZ, Leggio L. Advances in the science and treatment of alcohol use disorder. Sci. Adv. 5, eaax4043 (2019). Retrieved on January (2) 7, 2019 from https://advances.sciencemag.org/content/5/9/eaax4043

18. Powers MB, Vedel E, Emmelkamp MG. Behavioral couples therapy (BCT) for alcohol and drug use disorders: A meta-analysis. Clin Psych Revi. 2008; 28:952-962.

19. Carroll KM, Fenton LR, Ball SA. Efficacy of disulfiram and cognitive behavioral therapy in cocaine-dependent outpatients: a randomized placebo-controlled trial. Arch Gen Psychiatry. 2004;61:264-72

20. Walters D, Connor JP, Feeney GF, Young RM. The cost-effectiveness of naltrexone added to cognitive-behavioural therapy in the treatment of alcohol dependence. J Addict Dis. 2009;28:137-144.

21. Brian J. Sherman, Aimee L. McRae-Clark Pharmacotherapy. Author manuscript; available in PMC 2017 May 1. Published in final edited form as: Pharmacotherapy. 2016;36: 511-535. doi: 10.1002/phar.1747 
Table 1: Scales Raw Scores on ASSIST of All Case Studies

\begin{tabular}{|l|l|l|l|l|l|l|l|}
\hline Substances & \multicolumn{2}{l|}{ Case Study-1 } & \multicolumn{2}{l|}{ Case Study-2 } & \multicolumn{2}{l|}{ Case Study-3 } \\
\hline & $\begin{array}{l}\text { Scor } \\
e\end{array}$ & Risk Level & $\begin{array}{l}\text { Scor } \\
e\end{array}$ & $\begin{array}{l}\text { Risk } \\
\text { Level }\end{array}$ & Score & $\begin{array}{l}\text { Risk } \\
\text { Level }\end{array}$ \\
\hline Tobacco products & 30 & High & 1 & Low & 35 & High \\
\hline Alcoholic Beverages & 0 & Low & 32 & High & 12 & $\begin{array}{l}\text { Moderat } \\
\text { e }\end{array}$ \\
\hline Cannabis & 0 & Low & 0 & Low & 32 & High \\
\hline Cocaine & 32 & High & 0 & Low & 1 & Low \\
\hline $\begin{array}{l}\text { Amphetamine/ } \\
\text { stimulants }\end{array}$ & 1 & Low & 1 & Low & 0 & Low \\
\hline Inhalants & 1 & Low & 0 & Low & 1 & Low \\
\hline $\begin{array}{l}\text { Sedatives/ Sleeping } \\
\text { Pills }\end{array}$ & 15 & Moderate & 12 & $\begin{array}{l}\text { Moderat } \\
\text { e }\end{array}$ & 20 & $\begin{array}{l}\text { Moderat } \\
\text { e }\end{array}$ \\
\hline Hallucinogens & 1 & Low & 0 & Low & 1 & Low \\
\hline Opioids & 0 & Low & 0 & Low & 35 & High \\
\hline Other - specify & 1 & Low & 0 & Low & 1 & Low \\
\hline
\end{tabular}

ASSIT = Alcohol, Smoking and Substance Involvement Screening Test

Table 2: Scale Raw Scores on Addiction Severity Index of All Case Studies

\begin{tabular}{|l|l|l|l|}
\hline Problems & Case Study-1 & Case Study-2 & Case Study-3 \\
\hline & Severity profile & $\begin{array}{l}\text { Severity } \\
\text { profile }\end{array}$ & $\begin{array}{l}\text { Severity } \\
\text { profile }\end{array}$ \\
\hline Medical & 3 & 2 & 3 \\
\hline Employment & 5 & 8 & 2 \\
\hline Alcohol & 0 & 7 & 1 \\
\hline Drug & 9 & 9 & 9 \\
\hline Legal & 1 & 2 & 2 \\
\hline Family/social & 8 & 8 & 8 \\
\hline Psych & 0 & 0 & 0 \\
\hline
\end{tabular}


248 Table 3: Scales Raw Scores of Pre and Post Testing of All Case Studies

\begin{tabular}{|l|l|l|l|l|l|l|}
\hline Scales & \multicolumn{2}{l|}{ Case Study-1 } & \multicolumn{2}{l|}{ Case Study-2 } & \multicolumn{2}{l|}{ Case Study-3 } \\
\hline & $\begin{array}{l}\text { Pre- } \\
\text { Testing }\end{array}$ & $\begin{array}{l}\text { Post- } \\
\text { Testing }\end{array}$ & $\begin{array}{l}\text { Pre- } \\
\text { Testing }\end{array}$ & $\begin{array}{l}\text { Post- } \\
\text { Testing }\end{array}$ & $\begin{array}{l}\text { Pre- } \\
\text { Testing }\end{array}$ & $\begin{array}{l}\text { Post- } \\
\text { Testing }\end{array}$ \\
\hline NAS & 87 & 45 & 79 & 44 & 87 & 45 \\
\hline BSCS & 31 & 11 & 25 & 8 & 32 & 17 \\
\hline PSS & 37 & 21 & 35 & 24 & 39 & 26 \\
\hline ASHS & $80 \%$ & $50 \%$ & $90 \%$ & $50 \%$ & $80 \%$ & $60 \%$ \\
\hline RAS & -85 & -38 & -76 & -32 & -78 & -73 \\
\hline
\end{tabular}

249 Note: NAS= Novaco Anger Scale; BSCS= Brief Substance Craving Scale; 250 PSS= Perceived Stress Scale; ASHS= Adolescent Sleep Hygiene Scale; RAS= 251 Rathus Assertiveness Scale

Figure 1: Graphical presentation of pre- and post-testing scores of three 255 patients after Cognitive Behaviour Therapy

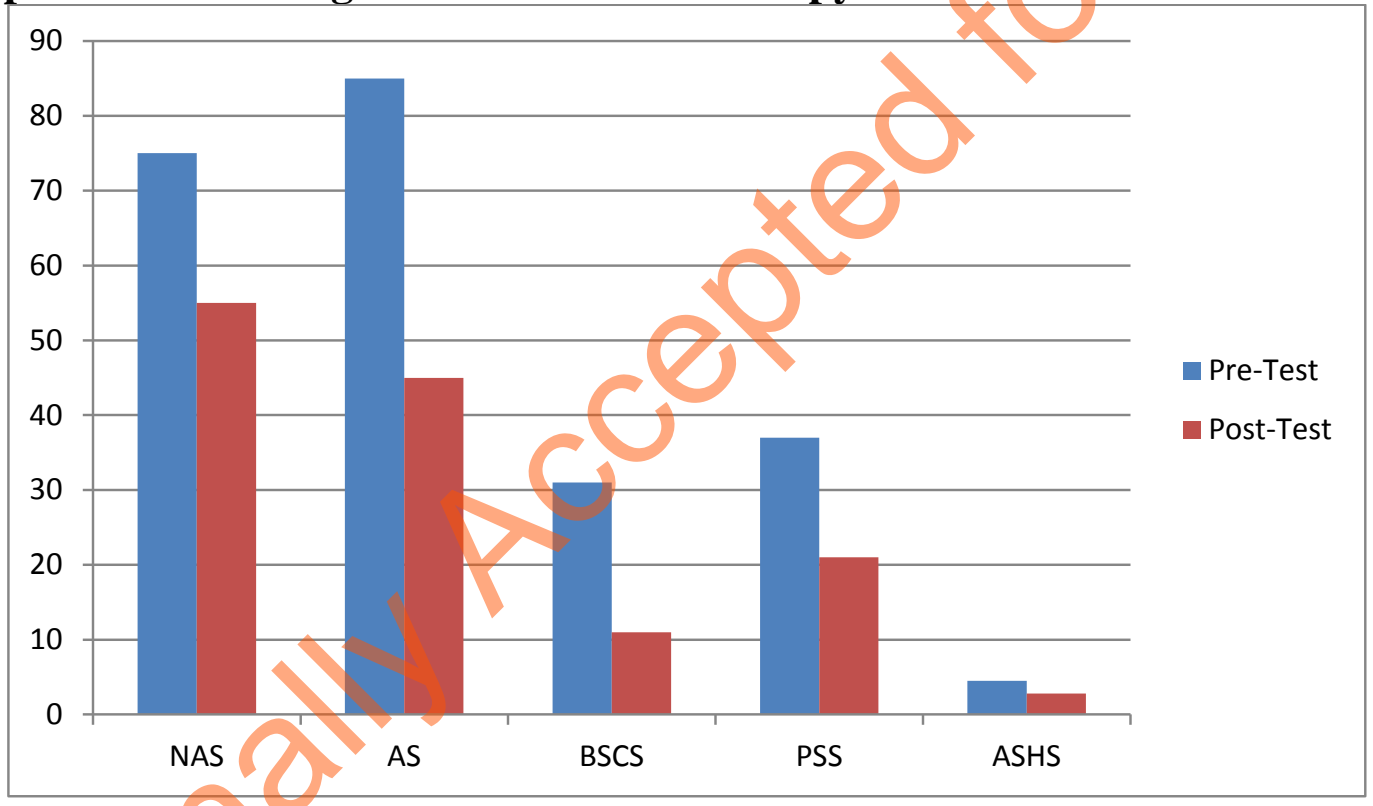

